九州大学学術情報リポジトリ

Kyushu University Institutional Repository

\title{
Tensile Properties of Kenaf/E-glass Reinforced Hybrid Polypropylene (PP) Composites with Different Fiber Loading
}

Sosiati, Harini

Mechanical Engineering Department, Faculty of Engineering, Universitas Muhammadiyah

Shofie, Yankeisna Auda

Mechanical Engineering Department, Faculty of Engineering, Universitas Muhammadiyah

Nugroho, Aris Widyo

Mechanical Engineering Department, Faculty of Engineering, Universitas Muhammadiyah

https://doi.org/10.5109/1936210

出版情報: Evergreen. 5 (2)，pp. 1-5，2018-06. 九州大学グリーンアジア国際リーダー教育センター バージョン:

権利関係 : 


\title{
Tensile Properties of Kenaf/E-glass Reinforced Hybrid Polypropylene (PP) Composites with Different Fiber Loading
}

\author{
Harini Sosiati*, Yankeisna Auda Shofie and Aris Widyo Nugroho \\ Mechanical Engineering Department, \\ Faculty of Engineering, Universitas Muhammadiyah Yogyakarta, Indonesia \\ *E-mail: hsosiati@ft.umy.ac.id
}

(Received November 15, 2017; accepted June 14, 2018)

\begin{abstract}
Kenaf/E-glass reinforced polypropylene (PP) hybrid composites with different fiber loading 20, 25 and 30 (vol. \%) were fabricated using a hot compression molding. The effect of the fiber content on the tensile properties of the composites was studied. The ratio of alkali-treated kenaf fiber and untreated E-glass fiber was 20:10 (vol. \%). The tensile strength and strain of the composites slightly decreased with the increase of the fiber content, but tensile modulus increased. The presence of voids and inhomogeneous distribution of the fibers led to the change of tensile properties of the composites as confirmed by scanning electron microscopy (SEM) micrographs of the tensile fracture surface.
\end{abstract}

Keywords: Kenaf fiber, glass fiber, hybrid composite, tensile properties, SEM

\section{Introduction}

Revolution in the automotive industry leads to the enhancement of air pollution coming from the emission of automobile gasses which would emerge a severe environmental problem worldwide. The awareness to overcome this issue has to be considerable attention. Reducing the weight of a vehicle by replacing the conventional metal (steel) with light-weight materials such as aluminum, magnesium and composite is one of some alternative solutions that could be proposed in the automotive design. In this case, the reduction of material weight could not only diminish the emission of gasses but also reduce the cost, engine, fuel consumption and structure [1].

In the case of design flexibility, corrosion resistant and mechanical properties, the use of composite material in an automotive application is beneficial. However, the cost of the element of composite materials: e.g. synthetic fiber (carbon fiber) reinforced polymer/plastic composites is much higher than that of the conventional metals [2]. The use of carbon fiber for industrial scale would consume very high cost.

Therefore, the interior and exterior parts of the automobile commonly use glass fiber reinforced plastic composites. A shortcoming of glass reinforced composites, however, is related to non-biodegradability, material recycling and the potential health hazard to human and environment [3].

The natural fiber composites have been recently developed for the automotive applications due to some advantageous properties of the natural fibers such as light in weight, affordable, abundantly available in the earth, biodegradable and non-abrasive. The manufacture of natural fiber composites includes the use of thermoplastics and thermosets as binders or matrix materials. Thermoplastic polypropylene (PP) is recently developed in the automotive application, especially for non-structural components owing to its advantageous properties such as low density, excellent processability, mechanical properties, electrical properties and excellent dimensional stability [1]. Natural fiber composite, however, has some limitations such as environmental durability, high-temperature exposure and incompatibility of natural fiber and polymer matrix [3].

Thus, the choice of composite material for the future automotive application should be the hybrid composite made of hybridization of the natural fiber and glass fiber, of course, with the mechanical properties classified in the range of industry standard material.

Kenaf fiber is one of some natural fibers used as the reinforcement of the thermoplastic composites [4] for automotive application due to its high tensile strength of the fiber [6]. Besides, it is abundantly available in this earth, especially in Asia [5] including Indonesia. Toyota Boshoku Corporation, Japan becomes a pioneer in using kenaf as a raw material for the interior automotive components [6].

The hybrid composite of the kenaf fiber/E-glass with thermoset polymers have been extensively studied [7, 8]. However, few studies of kenaf fiber/E-glass/PP hybrid composites have been reported. Kenaf/woven Eglass/polyester hybrid composites [7] revealed the highest tensile strength of around $120 \mathrm{MPa}$ higher than that of about 50 and $70 \mathrm{MPa}$ resulted from kenaf/glass/epoxy resin with the fiber orientation $0^{\circ}$ and $90^{\circ}$, respectively [8]. The effects of a fiber content and the ratio of glass fiber and kenaf fiber on stiffness of the kenaf/glass/PP composites indicated that a fiber content 
of $50 \mathrm{vol} \%$ and glass fiber/kenaf fiber ratio of 1 resulted in the highest stiffness at the modulus elasticity of 14.475 GPa [9].

To date the optimization of the fiber content related to mechanical properties of kenaf/glass/PP [9], banana fiber/glass/polyester and rice husk/glass/polyester [10], and woven kenaf/polyvinyl butyral resin (PVB) [11] composites has been still carried out. This indicates that the fiber loading plays a vital role in affecting the tensile properties of the polymer composites. The hybridization of kenaf and E-glass fibers for reinforcing the PP matrix in current work was studied by three variations of the fiber loading (20, 25 and 30 vol. \%). Those values were considered as the optimum range of the fiber loading. It is also related to the capability of the used compression molding in our facility. Some changes in tensile properties of kenaf/E-glass/PP hybrid composites were discussed due to the difference in the fiber content, morphology of the fibers and the tensile fracture surfaces.

\section{Experimental}

\subsection{Materials and Procedures}

Kenaf fiber, E-glass fiber, and PP sheet with the density of 1.5, 2.5 and $0.92 \mathrm{~g} / \mathrm{cm}^{3}$ were purchased from Balittas-Malang, Indonesia, PT. Justus Kimia RayaSemarang, Indonesia and PT. Sumber Jaya, Indonesia, respectively. Kenaf fibers were washed with water to remove the contaminant and dirt present on the fiber surface. The fibers were then soaked in $6 \% \mathrm{NaOH}$ solution for $4 \mathrm{~h}$ at room temperature (RT) to eliminate a part of the non-cellulosic components such as hemicelluloses and lignin to make better bonding strength between the fiber surface and the matrix. Subsequently, the fibers were washed with flushing water and dried in an oven at $100^{\circ} \mathrm{C}$ for $30 \mathrm{~min}$. Alkali-treated kenaf and untreated E-glass fibers were chopped into 5 $\mathrm{mm}$ length, and PP sheets were cut into $17 \mathrm{~mm}$ length and $2 \mathrm{~mm}$ width (Fig. 1).

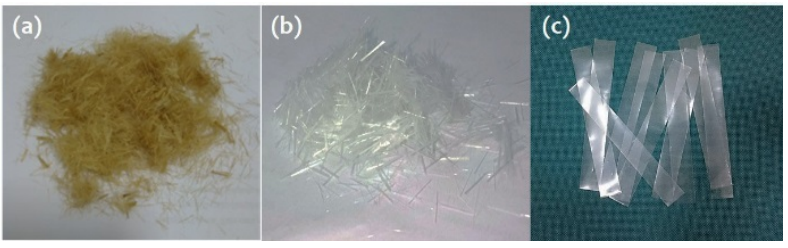

Fig. 1: Chopped kenaf fibers (a) and E-glass fibers (b), and cut PP sheets (c) used in the hybrid composite fabrication.

The fabrication of kenaf/E-glass/PP hybrid composites was carried out by means of sandwiching technique in a hot compression molding, as described elsewhere [12]. E-glass and kenaf fibers were manually mixed, arranged between the PP sheets into 13 laminates in a Fe-mold with the dimension of $17 \mathrm{~cm}$ length, $2.2 \mathrm{~cm}$ width, and $2 \mathrm{~cm}$ depth and then hot pressed at around $170^{\circ} \mathrm{C}$ and 2-3 MPa for about $10 \mathrm{~min}$. The fiber content was varied in 20, 25 and 30 vol. \%. The ratio of kenaf and
E-glass fibers was fixed 20/10. In this study, each variation of the fiber content was prepared at least seven composite sheets (specimens) for the tensile test. One of them is shown in Fig. 2 (the bottom).

\subsection{Tensile Test}

Tensile tests were done on the single fiber (kenaf and E-glass fibers) and kenaf/E-glass/PP hybrid composites using a universal testing machine (SFL-20-350, Shimadzu). The tensile test specimens were prepared based upon ASTM C1557-03 for the single fiber and ASTM D638-02 for kenaf/E-glass/PP hybrid composites.

Kenaf/E-glass/PP hybrid composite specimens were tensile tested at a maximum load cell of $2 \mathrm{kN}$, a crosshead speed of $500 \mathrm{~mm} / \mathrm{min}$ and a gauge length of $50 \mathrm{~mm}$. Prior to the tensile testing, the fabricated hybrid composite sheets were prepared to be the tensile test specimens (ASTM D638-02) using a computer numerical control (CNC) machine as shown in Fig. 2 (the top).

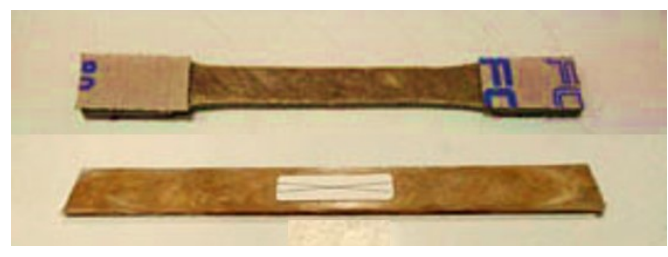

Fig. 2: Profile of the hybrid composite sheet (the bottom) and the tensile test specimen (the top).

\subsection{Characterization}

Fourier transform infrared (FTIR) spectroscopy (Shimadzu) was performed to characterize the chemical composition contained in the untreated and alkali-treated kenaf fibers qualitatively: i.e. the presence of noncellulosic components of hemicellulose and lignin. The morphology of kenaf and E-glass fiber surfaces and tensile fracture surface of the hybrid composite specimens were examined by scanning electron microscopy (SEM, TESCAN VEGA3 LMU) operating at $15 \mathrm{kV}$. Before SEM observation the specimen surface was metallic coated with Au-Pd.

\section{Results and Discussion}

\subsection{Tensile properties of the fibers}

The tensile strength and modulus of single alkalitreated kenaf fiber used in this work is $202.39 \mathrm{MPa}$ and 14. $04 \mathrm{GPa}$, respectively. Those measures are nearly similar to the properties of kenaf fiber reported by Ostruck [7], viz. $223 \mathrm{MPa}$ and $15 \mathrm{GPa}$, respectively. Also, the diameter of kenaf fiber seems to be almost the same, ranging from 80 to $150 \mu \mathrm{m}$. The tensile strength of this alkali-treated kenaf fiber is higher than that of the untreated kenaf $175 \mathrm{MPa}$ [13]. This difference value has verified that alkalization by soaking in $6 \% \mathrm{NaOH}$ at RT for $4 \mathrm{~h}$ could significantly enhance the tensile properties of single kenaf fiber. However, those tensile properties are much lower in comparison with the properties of kenaf fiber reported in another work, viz. $930 \mathrm{MPa}$ and $53 \mathrm{GPa}$, respectively [9]. 
The tensile strength of E-glass fiber used in this study is $3.71 \mathrm{GPa}$, nearly similar to the one reported by Holbery et al. [3]: i.e. 2-3.5 GPa, but it is much lower compared to the one reported by Mansor et al. [9]: i.e. $70 \mathrm{GPa}$.

In this case, such physical and mechanical properties of single natural fiber cannot be compared accurately to each other for being influenced by many factors such as the fiber origin, the age of the fiber and harvest time. Even though the fibers contained in a similar fiber bundle, they possibly has some different properties to each other due to the discrepancies in cellulosic and the noncellulosic contents [14]. Also for glass fiber, there are some kinds of E-glass fiber.

\subsection{FTIR of kenaf fiber}

FTIR spectra of untreated and alkali-treated kenaf fibers (Fig. 3) depicted a distinct discrepancy. The broad peak at $3410 \mathrm{~cm}^{-1}$ is characteristic -OH stretching vibration of the hydroxyl band. A strong peak at 2924 $\mathrm{cm}^{-1}$ corresponds to $\mathrm{C}-\mathrm{H}$ stretching vibration. A sharp peak at $1734 \mathrm{~cm}^{-1}$ observed in untreated kenaf is attributed to the carboxylic group $(=\mathrm{C}=\mathrm{O})$ corresponding to hemicelluloses [15]. The disappeared peak at 1734 $\mathrm{cm}^{-1}$ in alkali-treated fiber indicates that hemicelluloses

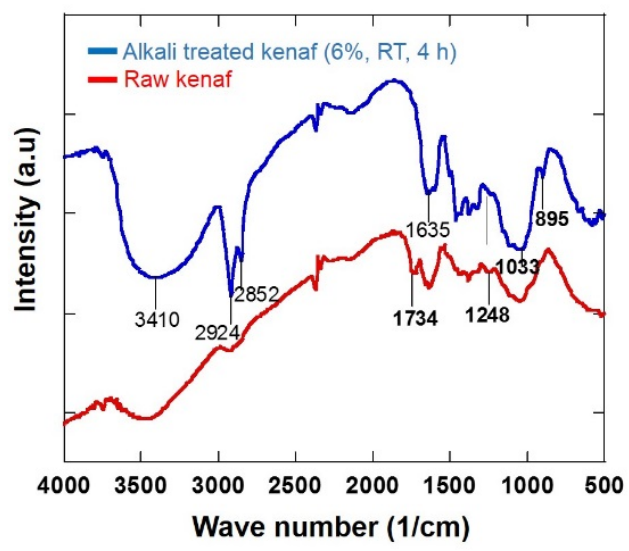

Fig. 3: FTIR spectra of untreated and alkali treated kenaf fibers.

were removed after alkalization. The $\mathrm{OH}$ bending of absorbed water was identified in both spectra in the position of around $1635 \mathrm{~cm}^{-1}$ [16]. The band around 1248 $\mathrm{cm}^{-1}$ is related to C-O ring of both lignin and pectin [17]. The very small peak at this position identified in alkali treated-kenaf suggested that less amounts of residual lignin remain in alkali-treated kenaf. The peak near 1420 $\mathrm{cm}^{-1}$ and $895 \mathrm{~cm}^{-1}$ is the characteristic of the absorption of $\mathrm{CH}_{2}$ group present in cellulose and $\beta$-glycosidic linkages [18].

\subsection{Morphology of the fibers}

SEM micrographs of untreated kenaf, alkali-treated kenaf and E-glass fiber surfaces (Fig. 4a, 4b and 4c, respectively) demonstrate a different feature. The chemical composition of natural fiber mainly consists of cellulose, hemicelluloses and lignin. Cellulose microfibrils embedded in hemicelluloses in which lignin connected a network of microfibrils [19]. The difference in the surface morphology of untreated kenaf fiber (Fig. 4a) and the alkali-treated kenaf fiber (Fig. 4b) can be explained as follows. After alkalization, the striationslike structure on the fiber surface (Fig. 4b, see arrows) was formed due to the elimination of whole hemicelluloses from the fiber surface and cellulose microfibrils still keep connected with each other by the presence of some residual lignin, as confirmed from a FTIR result (Fig. 3). The trend of formation of the kenaf fiber surface structure due to alkalization has also been reported [20]. But the structure is dependent upon the alkalization condition. Cellulose microfibrils would separate from each other by the high concentration of alkali solution or hot alkalization [20].

A SEM micrograph of the surface of untreated Eglass fiber shows the different morphology (Fig. 4c): i.e. the fiber diameter of E-glass $(\sim 50 \mu \mathrm{m})$ smaller than that of kenaf fiber $(\sim 80-150 \mu \mathrm{m})$ with very smooth fiber surface.

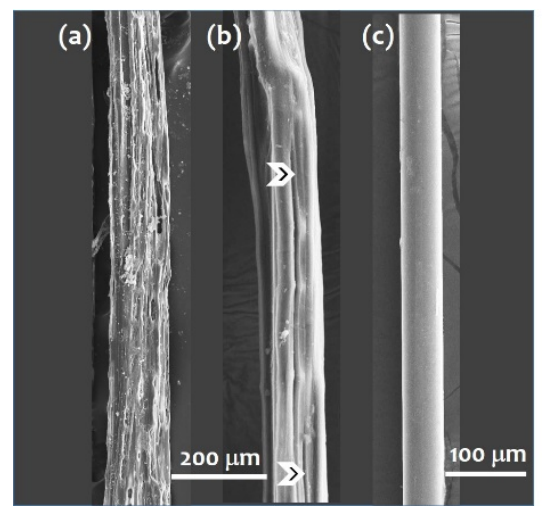

Fig. 4: SEM micrographs of untreated (a) and alkalitreated (b) kenaf fibers, and E-glass fiber (c).

Alkalization made the cellulose microfibrils exposed to the air by improving the hydroxyl groups and the fiber to be more hydrophilic. However, the existence of residual lignin inside the fiber can reduce hydrophilicity of the fiber, because lignin is naturally hydrophobic [21]. Thus, the present alkalization condition is considered to be an advantage.

\subsection{Tensile properties of kenaf/E-glass/PP composites}

The tensile properties of kenaf fiber/E-glass/PP hybrid composites showed that the increase of the fiber loading increases the tensile modulus and slightly decreases the tensile strength (Fig. 5). This result is attributed to decrease of the tensile strain: i.e. 0.060, 0.049 and $0.040 \mathrm{~mm} / \mathrm{mm}$ with the increase of the fiber content of 20, 25 and 30 vol. \%, respectively. The trend of the present result agrees with was studied by Salman et al. [11], indicating that the strain decreased with the increase of the fiber content from $10 \%$ to $50 \mathrm{vol}$. \%. They stated that low fiber content made an insufficient mix with a polymer matrix, for being high in a polymer matrix, leading to be higher in the elongation. Thus, the lower the 
fiber content resulting in more moderate stiffness which is also consistent with the result reported by Mansor et al. [9] who have also studied the hybrid composite of kenaf/glass fiber/PP.

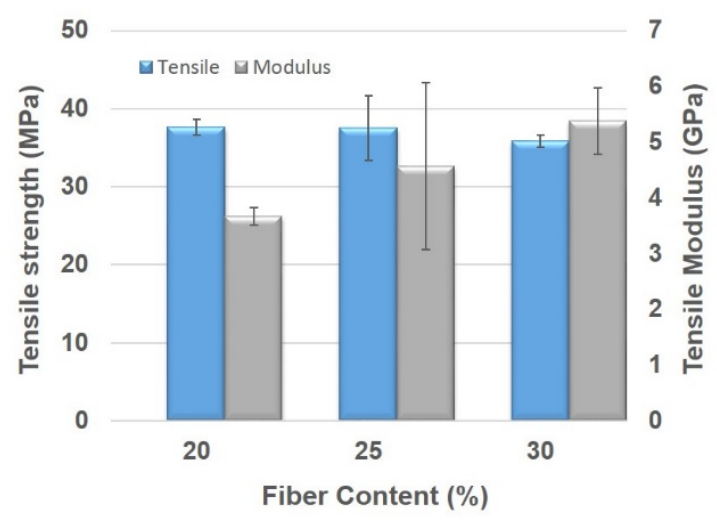

Fig. 5: Effect of the fiber content on the tensile strength and modulus of kenaf/E-glass/PP hybrid composites.

Referring to the tensile tested specimens as represented in Fig. 6 it is shown that some fracture (failed) areas were located at the position out of the gauge length (see arrows). We supposed that the fibers were inhomogenously distributed within the matrix due to a manual fabrication of these hybrid composites. It is also corresponding to the interfacial bonding between the fibers (kenaf and E-glass fibers) and the PP matrix. The following results can also explain the differences in the tensile properties.

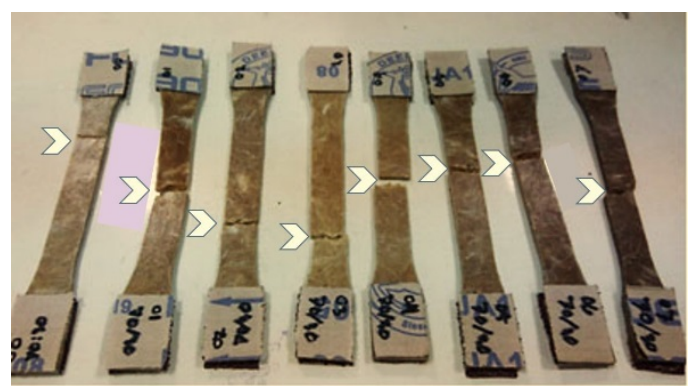

Fig. 6: Profile of the tensile tested hybrid composite specimens showing the position of fracture areas (see arrows).

\subsection{Tensile fracture surface}

The alteration of tensile properties of the hybrid composite kenaf/E-glass/PP due to the different fiber loading can be explained by the changing structure of fracture surface (Fig. 7). SEM micrographs of the tensile fracture surface on all hybrid composite specimens revealed some micro-voids (see big white arrows). The microstructure of specimen with 20 vol. \% fiber loading, however, appears slightly denser (Fig. 7a) than that of the other two (Fig. 7b and 7c), shown in detail in a magnified image (Fig. 7a') of a square area in Fig. 7a. This microstructure feature reflects on the slightly higher in tensile strength of the specimen with 20 vol. \% fiber loading compared to the specimens with fiber loading of 25 and 30 vol. \% (Fig. 5). The higher the fiber loading resulted in inhomogeneous fiber dispersion within a polymer matrix, for being excess in fiber, leading to be lower in tensile strength.

SEM micrographs (Fig. 7) also reveal that the distribution of kenaf fibers and E-glass fibers distinctly form layer by layer, suggesting the inhomogeneous distribution of the fibers in the matrix. It might be caused by a manual technique in mixing the fibers during the composite fabrication.
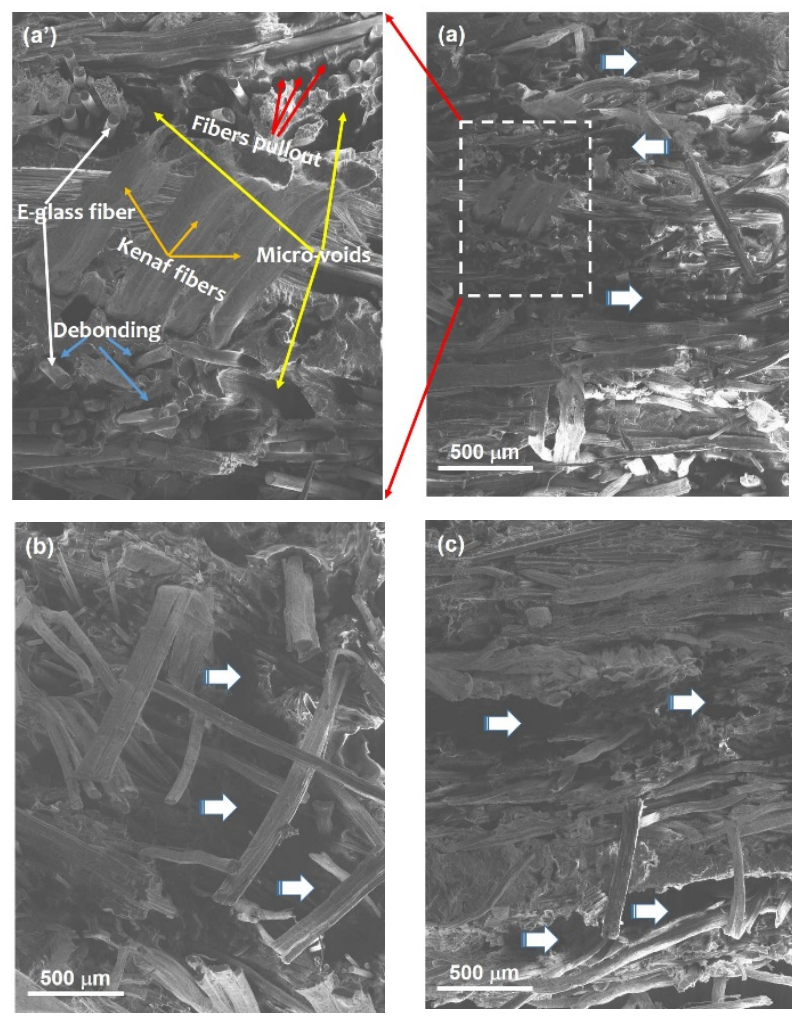

Fig. 7: SEM micrographs of tensile fracture surface on kenaf/E-glass/PP hybrid composites with different fiber loading, (a) 20 vol. \%, (a') a magnified image of a rectangular dash line area in (a), (b) 25 vol. \% and (c) 30 vol. \%.

Besides, the fiber de-bonding and fiber pullout are seen mainly on E-glass fiber, but not on kenaf fiber indicating that the interfacial bonding between kenaf fiber and the PP matrix is better than that of E-glass fiber and the PP matrix. This result is affected by the difference in surface morphology of kenaf fiber and E-glass fiber as described in Subsection 3.3.

The E-glass fiber used in a study of sisal/E-glass/PP hybrid composite was heat-treated at $500^{\circ} \mathrm{C}$ for $4 \mathrm{~h}$ to remove sizing agent [22]. The interfacial bonding of Eglass and PP matrix was better than that of this work. On the other hand, it has been reported that the silanated glass fiber (industrially treated) improved the surface energy resulting in the better adhesion to the polymer matrix [23]. Nevertheless, the tensile strength (37.61 
$\mathrm{MPa}$ ) and modulus (5.40 GPa) of the present kenaf/Eglass/PP hybrid composites are higher than those of other studies: i.e. $29.70 \mathrm{MPa}$ [21] and 4.53 GPa [9], respectively. That comparison is based on the similar fiber loading (30 vol. \%) and the ratio of the natural fiber to E-glass fiber (20 to 10).

The untreated E-glass fiber used in this study affects the formation of fiber de-bonding and fiber pullout, leading to the chance reduction of transfer stress from the matrix to the reinforcing material. It seems to be less contribution of glass fiber to withstand the applied load decreases the tensile strength.

In addition, better improvement the flexural stress due to alkali-treated fiber (30.25 $\mathrm{MPa}$ ) compared to the untreated fiber (19.92 MPa) has been reported in kenaf/PP composites with the fiber content of $20 \%$ [24]. Kenaf/glass/epoxy hybrid composite has also shown higher flexural strength by using alkali-treated kenaf (68 $\mathrm{MPa})$ than the untreated kenaf (60 $\mathrm{MPa})$ [25]. Summarizing results indicate that in addition to the fiber content, the quality of reinforcing fibers affected by the treatment condition would also work significantly in influencing the mechanical properties of the related composite.

\section{Conclusion}

The hybrid composites of kenaf/E-glass/PP have been successfully fabricated using a hot compression molding with relatively high tensile strength of $37.61 \mathrm{MPa}$ at the fiber loading of $20 \mathrm{vol}$. \%. A different fiber loading in the tight range of $20 \%$ to $30 \mathrm{vol}$. \% did not show a significant change in tensile properties. It has been verified that the use of untreated E-glass fiber was not beneficial, for forming fiber de-bonding and fiber pullout and then bringing an impact on the mechanical properties. The reinforcing fiber condition is also an essential parameter other than the fiber content.

\section{Acknowledgements}

The present work was partly supported by "Unggulan Prodi” Research Grant, Universitas Muhammadiyah Yogyakarta (UMY). The authors would like to acknowledge Mechanical Engineering Department, Faculty of Engineering, UMY for supporting the research facilities.

\section{References}

1) P. E. Bourban, N. Bernet, J. E. Zanetto, J. Anders and E. Månson, Compos. Part A, 32, 8, 1045 (2001).

2) A. John and S. Alex, Int. J. Eng. Manag. Res., 4 (4) 98 (2014).

3) J. Holbery and D. Houston, JOM, 58, 80 (2006).

4) M. Jawaid and H. abdul Khalil, Carbohydrate Polymers, 86 (1) 1 (2011).

5) I.A.S. Salem, A.R. Rozyanty, B.O. Betar, T. Adam, M. Mohammed, and A.M. Mohammed, J. Physics: Conf. Series, 908, 012001 (2017).

6) J. Kamal, M. Zharif Thirmizir, E. Beyer, M.J. Saad, N.A. Abdul Rashid, and Y. Abdul Kadir, J. Sci. Technol, Available
file://C:/Users/ASUS/Downloads/796-3588-1PB\%20(1).pdf

7) Z. Öztürk, J. Comp. Mater., 44, 2265 (2010).

8) M. Ramesh and S. Nijanthan, Bull. Mater. Sci., 39, 1, 147 (2016).

9) M. R. Mansor, S. M. Sapuan, E. S. Zainudin, A. A. Nuraini and A. Hambali, J. Polym. Mater., 30, 3, 321 (2013).

10)G. Gupta, A. Gupta, A. Dhanola and A. Raturi, IOP Conf. Series: Mater. Sci. Eng., 149, 012091 (2016).

11)S. D. Salman, Z. Leman, M. T. H. Sultan, M. R. Ishak and F. Cardona, Int. J. Polym. Sci., 2016, 1 (2016).

12)H. Sosiati, A. Nahyudin, I. Fauzi, D. A. Wijayanti and K. Triyana, AIP Conf. Proc., 1725, 010081 (2016).

13) H. Sosiati, H. Pratiwi, D. A. Wijayanti and Soekrisno, Adv. Mater. Sci., 1123, 147 (2015).

14) M. M. Kabir, H. Wang, K. T. Lau and F. Cardona, Compos. Part B, 43, 7, 2883 (2012).

15) J. I. Moran, V.A. Alvarez, V.P. Cyras and A. Vázquez, Cellulose, 15, 149 (2008).

16) N. Nosbi, H.M. Akil, Z.A.M. Ishak and A. Abu Bakar, BioResources, 6, 2, 950 (2011).

17) A. Kumar, Y.S. Negi, V. Choudhary and N.K. Bhardwaj, J. Mater. Phys. Chem., 2, 1, 1 (2014).

18) P. K. Adapa, C. Karunakaran, L. G. Tabil and G. J. Schoenau, Agric. Eng. Int., 9, 1 (2009).

19) G. Siqueria, J. Bras and A. Dufresne, Polymers, 2 (4), 728 (2010).

20)H. Sosiati and Harsojo, Cellulose Chem. Technol., 48 (1-2), 33 (2014).

21)M. J. John and R. D. Anandjiwala, Polym. Compos., 29, 2, 187 (2008).

22)K. Jarukumjorn and N. Suppakarn, Composites B, 40, 623 (2009).

23)R. B. Fonseca, M. S. D. Paula, A. V. B. Kasuya, G. A. M. Mendes, I. N. Favarão, L. N. D. Almeida and H. L. Carlo, BioMed, Res. Int., 2014, 1 (2014).

24) M.M. Husin, M.S. Mustapa, M.S. Wahab, A.M.T. Arifin, M.I.M. Masirin and F.H. Jais, AIP Conf. Proc., 1846, 020008 (2017).

25) Y.H. Mohammad, S. Ahmad, M.A. Abu Bakar, A.A. Mamun and H.P. Heim, J. Reinforced Plastics and Composites, 34, 11, 896 (2015). 